\title{
Performance Analysis of Heterogenous WSN for Application in loT
}

\author{
T. M. BEHERA*, S. K. MOHAPATRA and O. P. ACHARYA \\ School of Electronics Engineering, Kalinga Institute of Industrial Technology \\ Bhubaneswar, India.
}

\begin{abstract}
Extending the Internet to connect any physical device with smart technology can be called as the Internet of Things (IOT).It is a proposed development of the Internet in which everything can be connected to the internet enabling them to send and receive data. Selection of energy efficient routing protocols has become an essential step in designing any loT network. Moreover, the protocol should also be selected to enhance the lifetime of the network. In this article, we evaluate the performance analysis of DEEC (Distributed Energy Efficient Clustering), DDEEC (Developed DEEC), EDEEC (Enhanced DEEC) and TDEEC (Threshold DEEC) for the application in loT. From MATLAB simulation, it was observed that TDEEC outperforms other routing protocols and is well suited for loT application.
\end{abstract}

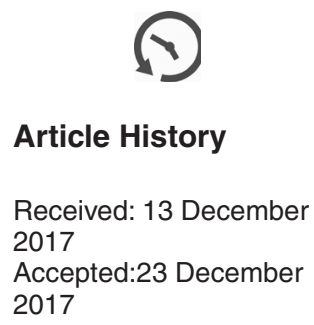

Keywords

IoT,

WSN

DEEC,

DDEEC

EDEEC,

TDEEC.

\section{Introduction}

IoT includes three major components for seamless communication between the source and end user. The first is the hardware which is comprised of sensors or actuators and entrenched communicating hardware like Radio Frequency Identification (RFID), Wireless Sensor Network (WSN), etc. The second is a middleware which performs on-demand storage and computing tools for data analytics. The last part of IoT is a presentation of novel and easy to understand conception and interpretation tools that can be widely accessed on different platforms that are designed for different applications ${ }^{1}$.
The emerging IoT has a diversified application scenario equipped with a wide range of heterogeneous devices. As WSN also has a wide range of application in the various working domain and is also well suited for long-term data acquisition, hence WSN will be the best sensor interfacing device in the loT environment ${ }^{2,3}$.

The WSN especially consists of distributed autonomous sensors which monitored environmental or physical conditions like temperature, pressure, sounds, etc. and passes their sensed information through the path to the main location ${ }^{4}$. These paths

\footnotetext{
CONTACT T. M. Behera truptifet@kiit.ac.in $\mathbf{9}$ School of Electronics Engineering, Kalinga Institute of Industrial Technology, Bhubaneswar, India.

(C) 2017 The Author(s). Published by Techno Research Publishers

This is an 6 Open Access article licensed under a Creative Commons Attribution-NonCommercial-ShareAlike 4.0 International License (https://creativecommons.org/licenses/by-nc-sa/4.0/), which permits unrestricted NonCommercial use, distribution, and reproduction in any medium, provided the original work is properly cited.

To link to this article: http://dx.doi.org/10.13005/ojcst/10.04.05
} 
are made by using routing. The routing is a process of transmission of data from a source node to the destination node ${ }^{5}$. Various types of routing protocol are used for the communication purpose. These routing protocols are affected in WSN by several exigent factors like throughput, scalability, bandwidth utilization, network lifetime, etc. Cluster-based hierarchical routing protocols have been proved to have good energy utilization rate ${ }^{6}$ when compared to the non-cluster routing algorithm. The classification of a routing protocol can be done according to:

- the establishment of routing paths,

- $\quad$ the network structure,

- the protocol operation,

- $\quad$ the initiator of communications

- Selection of protocol based on the next hop on the route of the forwarded message.

When energy efficiency and stability is required, then the cluster-based routing protocols ${ }^{7}$ are incorporated. Energy-efficient protocols can be designed which will adapt with the various characteristics of WSNs, in order to enhance the network lifetime ${ }^{8}$. The hierarchical cluster-based protocol is more energy efficient because nodes with higher energy are random data selected to process the information and nodes with low energy are used to sense and send the data to the clustered $(\mathrm{CH})$. In this process, a lifetime of the network and stability period is increased. Distributed Energy-Efficient Clustering (DEEC) $)^{8,9}$ is one of the cluster-based hierarchical protocol used especially for multilevel communication in a heterogeneous routing environment. In DEEC ${ }^{10}$ protocol, the $\mathrm{CHs}$ are selected based on the ratio between the residual energy of each node and the average energy of the network ${ }^{8,11}$. The DEEC protocol functions with the estimation of the idealistic value of network lifetime in order to compute a reference energy which will be consumed by a node for each round. So that lower energy nodes have less probability than the higher initial and residual energy node to be the $\mathrm{CH}$. Thus DEEC protocol is more stable than the other heterogeneous protocols ${ }^{12}$.

\section{Heterogeneous WSN}

Most of the algorithms proposed for routing of data are meant to enhance the network lifetime and its stability period. The $\mathrm{LEACH}^{13}$ protocol was designed for a homogeneous sensor network. However, many algorithms have also been developed considering different heterogeneity levels in terms of energy. Depending on energy, the sensor nodes are categorized as normal nodes, advanced nodes or super nodes ${ }^{14}$. In a co-operative communication network, where the $\mathrm{CHs}$ need to communicate with each other, a low energy path is desired. DEEC is a clustering protocol for two and multilevel heterogeneous networks ${ }^{15}$.

\section{DEEC}

The DEEC protocol ${ }^{8}$ was proposed for networks with different energy level, where the selection of $\mathrm{CH}$ can be decided on the basis of both initial as well as residual energy. For homogenous networks all nodes are assigned with equal initial energy hence $p_{\text {opt }}$ is used for reference energy of probability pi. In this network, sensor nodes are either normal or advanced nodes. If $E_{0}$ is the energy given to normal node, then $E_{0}(1+a)$ be the energy assigned to advanced nodes, where ' $a$ ' will be the extra fraction of energy given to advanced nodes. If ' $m$ ' is the fraction of advanced sensors, then $\mathrm{N}(1-\mathrm{m})$ will be the amount of normal sensors and $\mathrm{Nm}$ is the total amount of advanced nodes. Hence the overall preliminary energy of the network is the summation of energies of normal as well as advanced nodes ${ }^{10}$ and is written as:

$$
\begin{aligned}
& \mathrm{E}_{\text {Total }}=\mathrm{N}(1-\mathrm{m}) \mathrm{E}_{0}+\mathrm{Nm}(1+\mathrm{a}) \mathrm{E}_{0} \\
& \mathrm{E}_{\text {Total }}=\mathrm{NE}_{0}(1+\mathrm{am})
\end{aligned}
$$

In a heterogeneous network, $p_{\text {opt }}$ depends on the value of initial energy of normal and advanced nodes; hence $\mathrm{p}_{\mathrm{opt}}$ can be given as:

$$
\begin{aligned}
& p_{a d v}=\frac{p_{o p t}}{1+a m} \\
& p_{n r m}=\frac{p_{o p t}(1+a)}{(1+a m)}
\end{aligned}
$$

If $E_{\text {avg }}$ is the average energy network for round $r$ then the probability of selecting $\mathrm{CH}$ can be given as 
$p_{i}=\left\{\frac{p_{o p t} E_{a v g}}{(1+a m)} ;\right.$ for normal modes

$p_{i}=\left\{\frac{p_{\text {opt }}(1+a) E_{\text {avg }}}{(1+a m) E_{\text {avg }}} ;\right.$ for advanced nodes

In multi-level networks, all the nodes are assigned with different energy levels. The primary power of nodes can be dispersed over a set ranging from $\left\{\mathrm{E}_{0}, \mathrm{E}_{0}\left(1+\mathrm{a}_{\max }\right)\right\}$ with $\mathrm{E}_{0}$ being the lower bound where amax is the value of the maximum energy assigned. The overall initial energy of the network can be given as:

$E_{\text {total }}=\sum_{i=1}^{N} E_{0}\left(1+a_{i}\right)=E_{0}\left(N+\sum_{i=1}^{N} a_{i}\right)$

Similarly for multilevel heterogeneous networks as written in ${ }^{8}$ can be given as:

$p_{\text {multi }}=\frac{p_{\text {opt }} N\left(1+a_{i}\right)}{\left(N+\sum_{i=1}^{N} a_{i}\right)}$

And the probability for the network can be given as:

$p_{i}=\frac{p_{\text {opt }} N(1+a) E_{\text {avg }}}{\left(N+\sum_{i=1}^{N} a_{i}\right) E_{\text {avg }}}$

If the overall energy of the sensing field is represented as $E_{\text {total }}$ and $E_{\text {round }}$ is the energy expended during each round, then the average energy of the field $E_{\text {avg }}$ for round $r$ can be given as:

$E_{\text {avg }}=\frac{1}{N} E_{\text {total }}\left(1-\frac{r}{R}\right)$

where $\mathrm{R}$ represents the number of rounds in the network given by $\mathrm{E}_{\text {total }} / \mathrm{E}_{\text {round }}$

DDEEC

In a two-level heterogeneous network as in DEEC, it becomes obvious for the advanced nodes to be elected as $\mathrm{CH}$ repeatedly due to more residual energy. As a result, there comes a point in the network, where all the advanced nodes will have the same residual energy as that of normal nodes. Hence to overcome this unbalanced situation, Distributed-DEEC was proposed to modify equations 8 and 9 by taking a threshold residual energy value as given in ${ }^{16}$ written as:

$T h_{\mathrm{Rev}}=E_{0}\left(1+\frac{a E_{d i s N N}}{E_{d i s N N}-E_{d i s A N}}\right) \square\left(\frac{7}{10}\right) E_{0}$

Under this condition, normal and advanced nodes will have the same probability to be elected as $\mathrm{CH}$. Therefore, the average probability for selection of $\mathrm{CH}$ is now rewritten as

$p_{i}=\left\{\frac{p_{\text {opt }} E_{\text {avg }}}{(1+a m) E_{\text {avg }}} ;\right.$ for normal nodes with $\mathrm{E}_{\text {avg }}>\mathrm{Th}_{\mathrm{Rev}}$

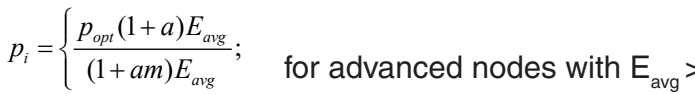
$\mathrm{Th}_{\mathrm{ReV}}$

$p_{i}=\left\{c \frac{(1+a) p_{\text {opt }} E_{\text {avg }}}{(1+a m) E_{\text {avg }}} ;\right.$ for normal and advanced nodes with $\mathrm{E}_{\mathrm{avg}}>\mathrm{Th}_{\mathrm{Rev}}$

\section{EDEEC}

It is a 3-level heterogeneous network with normal, advanced and super nodes ${ }^{10}$ categorized based on energy level. The normal and advanced nodes follow the same principle as that of the two-level network. The super-nodes of fraction ' $m_{0}$ ' have ' $b$ ' times more energy than normal nodes ${ }^{10}$. Hence the energy of super-nodes can be written as $\mathrm{E}_{0}(1+\mathrm{b})$. If the number of sensors in the network is $\mathrm{N}$, then $\mathrm{Nmm}_{0}$ is the number of super-nodes. Similarly, $\mathrm{Nm}\left(1-\mathrm{m}_{0}\right)$ will be the number of advanced nodes ${ }^{10}$. Hence the overall preliminary energy of the network is the summation of energies of all type of node, i.e. normal, advanced nodes and super-node which is given as:

$\mathrm{E}_{\text {Total }}=\mathrm{N}(1-\mathrm{m}) \mathrm{E}_{0}+\mathrm{Nm}\left(1-\mathrm{m}_{0}\right)(1+\mathrm{a}) \mathrm{E}_{0}+\mathrm{Nm}_{0} \mathrm{E}_{0}(1+\mathrm{b})$

$\therefore E_{\text {total }}=N E_{0}\left(1+m\left(a+m_{0} b\right)\right)$

The value of $p_{i}$ is given as: 


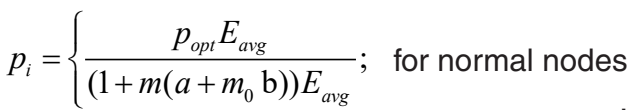

$p_{i}=\left\{\frac{p_{\text {opt }}(1+a) E_{\text {avg }}}{\left(1+m\left(a+m_{0} \mathrm{~b}\right)\right) E_{\text {avg }}} ;\right.$ for advanced nodes

$p_{i}=\left\{\frac{p_{\text {opt }}(1+b) E_{\text {avg }}}{\left(1+m\left(a+m_{0} \mathrm{~b}\right)\right) E_{\text {avg }}} ;\right.$ for super nodes

\section{TDEEC}

In TDEEC, for each round, every node decides to be a $\mathrm{CH}$ by choosing a number randomly between 0 and 1 . A threshold level $T_{s}$ is defined by equation 20 as given in ${ }^{17}$. Only when the number is less than $\mathrm{Ts}$, the node can be elected as $\mathrm{CH}$ for that particular round. If the optimal number of $\mathrm{CH}$ in the network can be written as $\mathrm{k}_{\mathrm{opt}}$, then $\mathrm{T}_{\mathrm{s}}$ is given as:

$T_{s}=\left\{\frac{p}{1-p(r \bmod p)} \times \frac{\text { Residual energy of a node } \times k_{\text {opt }}}{\text { Average energy of the network }}\right.$

\section{Simulation \& Result}

Considering 100 nodes deployed in a random manner in a network of $100 \mathrm{~m} \times 100 \mathrm{~m}$ to perform MATLAB simulation. The sink node is placed at the center of the network field and is assumed to have unlimited energy. Simulation for all the four protocols in two-level, 3-level heterogeneous WSN is done to evaluate the network performances. To generate MATLAB simulation, we consider these parameters as listed below.

\begin{tabular}{lr}
\hline Symbol & Value \\
\hline$m$ & 0.5 \\
$\mathrm{a}$ & 1.5 \\
$\mathrm{~b}$ & 3 \\
$\mathrm{~m}_{0}$ & 0.4 \\
$\mathrm{p}_{\mathrm{opt}}$ & 0.1 \\
$\mathrm{E}_{\mathrm{Rx}}$ & $0.0013 / \mathrm{pJ} / \mathrm{bit} / \mathrm{m}^{4}$ \\
$\mathrm{E}_{\mathrm{fs}}$ & $10 / \mathrm{pJ} / \mathrm{bit} / \mathrm{m}^{2}$ \\
$\mathrm{E}_{\mathrm{amp}}$ & $100 / \mathrm{pJ} / \mathrm{bit} / \mathrm{m}^{2}$
\end{tabular}

\begin{tabular}{lr}
$E_{\text {ele }}$ & $50 /$ nj/bit \\
$E_{T x}$ & $50 / n J / b i t$ \\
$E_{D A}$ & $5 / n J / b i t$ \\
$d_{0}$ & 87 meters \\
\hline
\end{tabular}

Figure 1 shows the number of nodes alive with each round. It was found that the first node for DEEC, DDEEC, EDEEC, and TDEEC dies at $1119,1404,1415,1482$ rounds respectively. It is clear that the TDEEC protocol is the most stable protocol out of DEEC, DDEEC and EDEEC. Since the probabilities of TDEEC and EDEEC are separately specified for each type of heterogeneous nodes, hence they have higher stability period than that of DDEEC and DEEC that uses same probabilities.

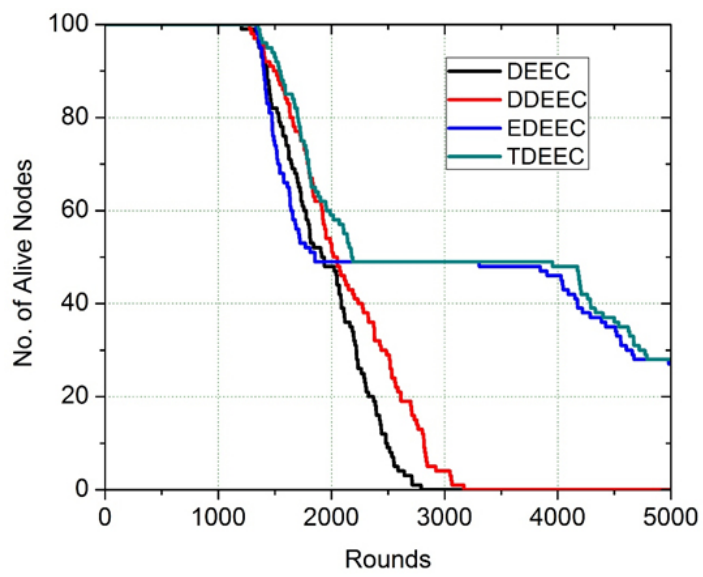

Fig. 1: No. of Alive nodes

The overall power consumption for the network for all the protocols can be evaluated from Figure 2. The initial energy for the normal node, advanced node, and super nodes are assumed to be $75 \mathrm{~J}$, $100 \mathrm{~J}$ and $123 \mathrm{~J}$ respectively. It is found that the energy dissipation rate is much slower for TDEEC and EDEEC as compared to DEEC and DDEEC due to the usage of different levels of energy in nodes. As a result, the network energy is totally dissipated at around 3000 rounds for DEEC and DDEEC whereas the nodes are still functioning for EDEEC and TDEEC even after 5000 rounds.

Figure 3 shows the data packets transferred to BS with each round. It can be seen that amount of data sent to base station rises in the initial rounds but gradually decreases due to the drainage of 
network energy. It is clear that TDEEC and EDEEC perform well as compared to DEEC and EDEEC

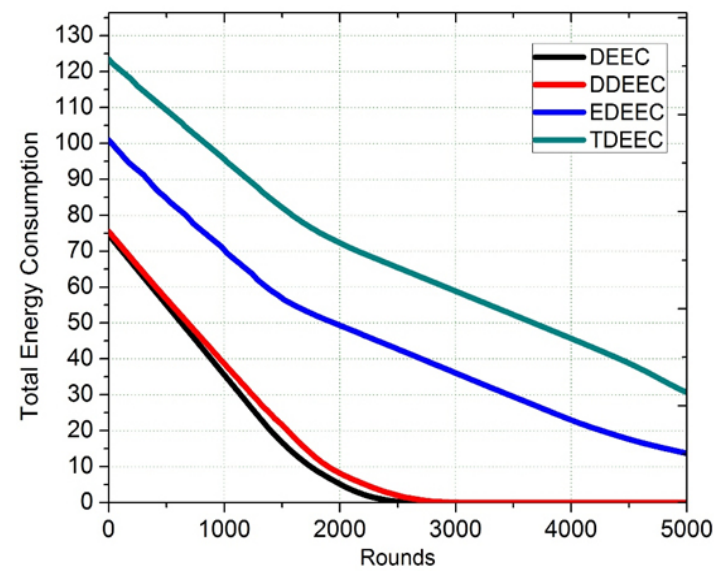

Fig. 2: Total Energy Consumption

\section{Conclusion}

One of the important applications of WSN is designing an IOT system. The sensors used for IoT should be able to sense the environment continuously as long as possible to transmit data to the end user. Communicating the data should be done in an efficient way to conserve energy in order to enhance the overall network lifetime. In this article, the performance analysis of heterogeneous sensor network with DEEC, DDEEC, EDEEC and TDEEC routing protocols have been done using MATLAB. It was found that the protocol using nodes of different energy levels performs well in terms of but a maximum number of data transfer occurs in case TDEEC.

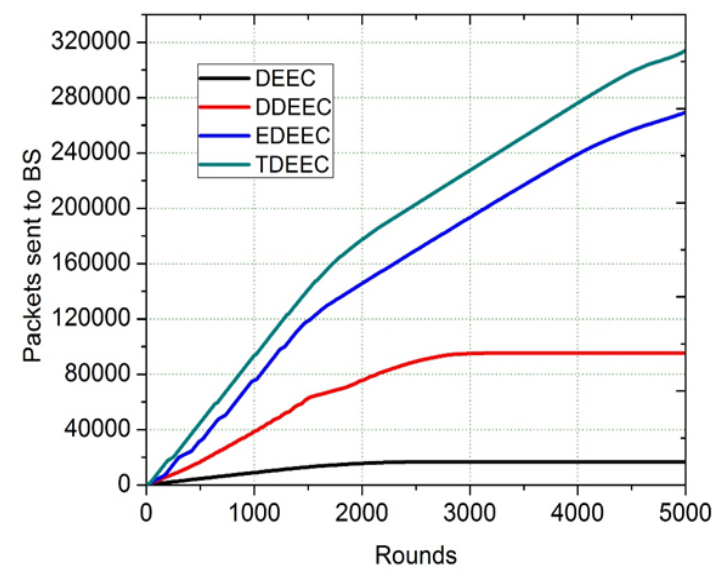

Fig. 3: Packets sent to BS

stability period, energy dissipation and throughput. Since TDEEC outperforms all other protocols it can be suggested for loT application.

\section{Acknowledgement}

The authors would like to thank to the School of Electronics Engineering, Kalinga Institute of Industrial Technology (Deemed to be University), Bhubaneswar, Odisha, India for providing the necessary financial support. We would also like to show our gratitude to the "anonymous" reviewers for their so-called insights.

\section{Reference}

1 A. P. Renold and R. J. Rani, "An internetbased RFID library management system," in Information \& Communication Technologies (ICT), 2013 IEEE Conference on, 2013, pp. 932-936.

2 P. Bellavista, G. Cardone, A. Corradi, and L. Foschini, "Convergence of MANET and WSN in loT urban scenarios," IEEE Sens. J., vol. 13, no. 10, pp. 3558-3567, 2013.
M. T. Lazarescu, "Design of a WSN platform for long-term environmental monitoring for loT applications," IEEE J. Emerg. Sel. Top. Circuits Syst., vol. 3, no. 1, pp. 45-54, 2013.
S. P. Singh and S. C. Sharma, "A survey on cluster-based routing protocols in wireless sensor networks," Procedia Comput. Sci., vol. 45, pp. 687-695, 2015.

5 L. Yadav and C. Sunitha, "Low Energy Adaptive Clustering Hierarchy in Wireless Sensor Network (LEACH)," Int. J. Comput. Sci. Inf. Technol., vol. 5, no. 3, pp. 4661-4664, 2014.

6 Y. Li, N.Yu, W. Zhang, W. Zhao, X. You, and M. Daneshmand, "Enhancing the performance of $\mathrm{LEACH}$ protocol in wireless sensor networks," in Computer Communications Workshops (INFOCOM WKSHPS), 2011 
IEEE Conference on, 2011, pp. 223-228.

W. B. Heinzelman, A. P. Chandrakasan, and H. Balakrishnan, "An application-specific protocol architecture for wireless microsensor networks," IEEE Trans. Wirel. Commun., vol. 1, no. 4, pp. 660-670, 2002.

8 L. Qing, Q. Zhu, and M. Wang, "Design of a distributed energy-efficient clustering algorithm for heterogeneous wireless sensor networks," Comput. Commun., vol. 29, no. 12, pp. 2230-2237, 2006.

9 N. Javaid, T. N. Qureshi, A. H. Khan, A. Iqbal, E. Akhtar, and M. Ishfaq, "EDDEEC: Enhanced developed distributed energyefficient clustering for heterogeneous wireless sensor networks," Procedia Comput. Sci., vol. 19, pp. 914-919, 2013.

10 T. N. Qureshi, N. Javaid, M. Malik, U. Qasim, and Z. A. Khan, "On performance evaluation of variants of DEEC in WSNs," in Broadband, Wireless Computing, Communication and Applications (BWCCA), 2012 Seventh International Conference on, 2012, pp. 162-169.

11 T. M. B. SK Mohapatra, P Mukherjee, HK Sahoo, "DEEC-VD: A Hybrid Energy Utilization Cluster-based Routing Protocol for WSN for application in IOT," in $16^{\text {th }}$ International Conference on Information Technology, 2017.

12 T. Sharma, B. Kumar, and G. S. Tomar, "Performance Comparision of LEACH, SEP and DEEC Protocol in Wireless
Sensor Network," in Proc. of the Intl. Conf. on Advances in Computer Science and Electronics Engineering, 2012.

13 M. J. Handy, M. Haase, and D. Timmermann, "Low energy adaptive clustering hierarchy with deterministic cluster-head selection," in Mobile and Wireless Communications Network, 2002. $4^{\text {th }}$ International Workshop on, 2002, pp. 368-372.

14 M. Naeem, M. Patwary, and M. Abdel-Maguid, "Universal and Dynamic Clustering Scheme for Energy Constrained Cooperative Wireless Sensor Networks," IEEE Access, 2017.

15 N. Javaid, S. N. Mohammad, K. Latif, U. Qasim, Z. A. Khan, and M. A. Khan, "HEER: Hybrid energy efficient reactive protocol for wireless sensor networks," in Electronics, Communications and Photonics Conference (SIECPC), 2013 Saudi International, 2013, pp. 1-4.

16 B. Elbhiri, R. Saadane, D. Aboutajdine, and others, "Developed Distributed Energy-Efficient Clustering (DDEEC) for heterogeneous wireless sensor networks," in I/V Communications and Mobile Network (ISVC), $20105^{\text {th }}$ International Symposium on, 2010, pp. 1-4.

17 P. Saini and A. K. Sharma, "Energy efficient scheme for clustering protocol prolonging the lifetime of heterogeneous wireless sensor networks," Natl. Inst. Technol. Jalandhar, Dep. Comput. Sci. Eng. Int. J. Comput. Appl., vol. 6, no. 2, 2010. 